\title{
The intellectual perception and some specific physical abilities as a function to predict the standard score of youth soccer players (16-18 years)
}

\author{
Adel Abdul Baser Ali HAITHAM
}

Department of Athletic Training and Kinetic Sciences, Faculty of Physical Education for Boys and Girls, Port Said University, Egypt. E-mail: hitham038@gmail.com

\begin{abstract}
This study aimed at identifying: Predictive equations of predicting with standard score of skill performance of soccer players with the significance of both intellectual perception and individually and collectively specific physical abilities to which they contribute. The research sample included 24 players in the age group of 16 - 18 years. They were intentionally selected from AlMasry Club, and Sports Port Fouad Club in Port Said. The researcher has used 22 players out of the basic sample, and from the same community to conduct a scoping study. The researcher has used the tests and measures to collect basic data for this study. The most important results indicated that The predictive equation of predicting the standard score of soccer players' performance from the age of 16- 18 years in the significance of specific physical abilities and the variables of the intellectual perception to which they contribute has been as follows: Standard score of the soccer players' performance from the age of 16-18 years $=-173.97-0.142$ (Kinetic Sense) -14.372 (Successive Stations) +0.181 (Barrow Zigzag Run Test) +0.389 (Bending the trunk to bottom) +6.326 (stop ball from different heights) 10.129 (Running for 30×5 times) +0.752 (Running for 3m) +0.996 (Associated Emotional Condition) + 0.997 (Auditory perception) + 1.382 (Standing Vertical Jump) + 0.092 (Wall Passing) + 8.727 (Running, walking for $800 \mathrm{~m})$.
\end{abstract}

Keywords: Sport, soccer training, male.

\section{INTRODUCTION}

Soccer is one of the activities of Physical Education that have a significant share of attention of practitioners, spectators, and researchers. Because of its benefits and physical and psychological values, it has become the most popular sport in the world. Therefore, most of the world countries are seeking to clearly raise the level of performance. Specialists in the field of training, such as, Rifai (9), Abdel Khaliq (1) suggested that the integration in the use of cognitive science such as biological, biochemical, sports psychology, sports sociology, biomechanics, and athletic training science led to a leap in the training field of various sports activities, which results appeared in all the World, European, regional and Olympic Championships. Soccer game has a significant portion of this progress, but there is still some questions related to the integration between the kinetic science and skill performance in soccer, which are searching for answers. In order to do that, the research and study should continue to answer them. Skill performance in soccer requires integration among the physical, physiological, psychological, biomechanical, training, and other factors to control the course of events during the games. It is noted from pursuing Local, International, Continental, Global, and Olympic soccer competitions that most wining cases are associated with how proficient the players are in performing the skill performance and high level of physical preparation in soccer.

The intellectual training is one of modern methods used to enhance the educational and training process, and it has become one of athletic training strategies because of its positive role in the evolution of the good level of skill and planning performance. Recent studies have concluded that the players who use the intellectual perception perform their athletic skills harder than those who do not use it (11).

Despite the importance of skill performance in soccer, and some researchers' interest in studying it Scriber (10), Moghnosi et al. (7), Towson (12), the researcher observed through his work in the training field of soccer that there are still deficiencies in the information availability about the importance of the relations among some variables such as intellectual training, specific physical abilities like explosive 
power, explosive power, speed endurance, and agility and the extent of its contribution to the skill level of the soccer players in some age phases. The researcher is prompted to address this current study, which is a "the intellectual perception and some specific physical abilities as a function to predict the standard score of skill performance of youth soccer players".

Therefore, this study aimed at identifying the contribution of each of the player's intellectual perception and some specific physical abilities such as the explosive power, explosive power, speed endurance, agility, and balance. It also aimed at identifying the extent of their contribution to improve the skill level of the soccer players, and how they can be used as a function to predict the standard score of skill performance of youth soccer players 16-18 years. These will increase our knowledge of some variables of intellectual perception and specific physical abilities that lead to improved skill performance in soccer, which helps those interested in soccer training of age group 16-18 years to develop training programs and loads to predict the level of skill performance with the significance of all physical abilities of some special physical, intellectual perception to which contribute in this age group.

\section{MATERIAL \& METHODS}

\section{Research Sample}

It included 24 players in the age group of 16-18 years. They were selected from Port Said Governorate clubs; Al-Masry Club (12 Players) and Port Fouad Sports Club (12 Players) in Egypt. The researcher also used 22 players out of the basic sample; Al-Masry Club (12 Players) and Port Fouad Sports Club (10 Players) and from the same community to conduct the pilot study.

\section{Data Collection}

The researcher has collected data by conducting tests and measures:

- Weighting: The researcher has used the medical balance to the nearest $1 / 2 \mathrm{~kg}$ weight to measure the players' weight.

- Measuring Height: The researcher has used Rest meter to measure the height to the nearest $1 / 2$ $\mathrm{cm}$.

Intellectual Perception Standard: The researcher has used the standard of intellectual perception in sports, Shimon (11). It has been applied to many Arab researches. The standard included four sports performances, which are individual performance, observing colleague, playing with others, and performance in the competition). Each of the above performance is responded to by a set of aspects, which are (visual perception, auditory perception, kinetic sense, associated emotional condition). This standard consists, amended in 1991, of 24 instead of 16 phrases, by 6 phrases for each position. The total number becomes 120 degrees, divided into 30 degrees for each position, 20 degrees, for each perception aspect. The degrees are calculated as follows: Phrases number 1 are collected in each position to represent the visual perception, and phrases number 2 are collected to represent auditory perception. Phrases numbers 3 are collected to represent the kinesthetic perception, and phrases numbers 4 are collected to represent the emotional perception. Phrases numbers 5 are collected to represent the control of perception, and phrases numbers 6 are collected to represent the internal perception.

The Measurements of Specific physical tests: The researcher has designed a form to poll the experts' views through conducting a survey of some references and researches' results that have been conducted on the soccer field, and that he could get them to identify all of specific physical abilities and the appropriate tests to measure each of them. The results of exploring experts' views, after the researcher selected the factors that have achieved $60 \%$ or more, were as follows: - Special physical abilities tests measured (8):

1. Transitive speed $100 \%$ (Running 30m)

2. Flexibility $85 \%$ (Bend the trunk forward to the bottom)

3. Agility $85 \%$ (Barrow Zigzag Run)

4. Explosive power $85 \%$ (Standing vertical jump)

5. Balance $81 \%$ (Stand metatarsal on wooden cube)

6. Performance speed $85 \%$ (Wall passing)

7. Accuracy $81 \%$ (Hit the ball with the sole of the foot side of the small goal )

8. Periodic respiratory Endurance 80\% (walk and running $800 \mathrm{~m}$ )

9. Performanceendurance $73 \%$ (Successive stations)

10. Speed Endurance (Running 30m x 5r) 
11. Co-ordination $71 \%$ (Stop ball from different heights)

- Basic Skills Tests: The researcher has designed a form to poll the experts' views through conducting a survey of some references and the researches' results conducted in soccer field that he could obtain to determine both the most basic skills and appropriate tests to measure each of them. The results of the survey to poll the experts' views after the researcher selected the factors that have achieved $60 \%$ or more were as follows:

- Basic Skills:

1. Kicking the ball for the longest distance $85 \%$.

2. Scoring on soccer goalkeeper $87 \%$.

3. Soccer ball outside foot running $85 \%$.

4. Soccer ball control $85 \%$.

5. Hit the ball with the head farthest distance $71 \%$.

6. Throw-in from the movement $71 \%$.

- The appropriate skill tests for the soccer players of age16-18 years: ( 8 )

1. Zigzag running with soccer ball $85 \%$.

2. Hit the ball with the head farthest distance $85 \%$.

3. Hit the ball with the sole of the foot side of the small goal $78 \%$.

4. Kicking the ball for the longest distance 81 $\%$.

5. Dribbling the ball on both feet $80 \%$.

6. Throw-in to the farthest distance $79 \%$.

- The scientific parameters of the tests used in the research: After identifying the specific physical, skill and intellectual tests under study, the researcher has conducted scientific parameters for each Appendix 1, 2 demonstrate the validity coefficient of the specific physical tests, intellectual training, and skill tests of soccer players (16 - 18 years). Appendix 3, 4 demonstrate the reliability coefficients of specific physical, intellectual perception and skill tests under study. To determine the degree of skill performance of soccer players, the researcher transformed the raw scores for each skill test to standard scores. The average of standard scores of the skill tests have been calculated, where the average value has been the standard score of the soccer players Tables 1, 2 demonstrate both the percentile score of skill tests and standard score of skill performance, respectively.

\section{Statistical Treatment}

The researcher has used the statistical package for the social sciences (SPSS) in the statistical treatment.

\section{RESULTS}

Tables 3 to 5 demonstrate The Ultimate Step of the Stepwise regression Analysis of the variables of visual perception, auditory perception, kinetic sense, associated emotional condition on the standard score of skill performance of soccer players (1618years). They also demonstrate The Ultimate Step of the stepwise regression analysis of specific physical abilities on the standard score of skill performance of soccer players, and also demonstrate TheUltimate Step of the stepwise regression analysis of the variables of visual perception, auditory perception, kinetic sense, the associated emotional condition, and specific physical variables on standard score of skill performance of soccer players.

Table 1. The scores of skill performance of the research sample members.

\begin{tabular}{|c|c|c|c|c|}
\hline Variables & $\begin{array}{c}\text { Measurement } \\
\text { Unit }\end{array}$ & Mean & $\pm \mathrm{SD}$ & $\begin{array}{c}\text { Skewness } \\
\text { Coefficients }\end{array}$ \\
\hline Kicking the ball for the longest distance & m. & 24.270 & 7.102 & 0.820 \\
\hline Zigzag running with soccer ball & Sec. & 25.900 & 2.400 & -2.436 \\
\hline Hit the ball with the sole of the foot side of the small goal & point & 40.500 & 2.00 & -0.420 \\
\hline Dribbling the ball on both feet & Sec. & 43.830 & 19.162 & -0.434 \\
\hline Hit the ball with the head farthest distance & m. & 10.510 & 1.200 & -0.378 \\
\hline Throw-in to the farthest distance & $\mathrm{m}$. & 10.520 & 2.500 & 0.990 \\
\hline
\end{tabular}


Table 2. The percentile scores of skill tests.

\begin{tabular}{cccccccc}
\hline $\begin{array}{c}\text { Percentile } \\
\text { score }\end{array}$ & $\begin{array}{c}\text { Kicking the ball } \\
\text { for the longest } \\
\text { distance }\end{array}$ & $\begin{array}{c}\text { Zigzag } \\
\text { running }\end{array}$ & $\begin{array}{c}\text { Hit the ball with the } \\
\text { sole of the foot side } \\
\text { of the small goal }\end{array}$ & $\begin{array}{c}\text { Dribbling } \\
\text { the ball on } \\
\text { both feet }\end{array}$ & $\begin{array}{c}\text { Hit the ball with } \\
\text { the head farthest } \\
\text { distance }\end{array}$ & $\begin{array}{c}\text { Throw-in to } \\
\text { the farthest } \\
\text { distance }\end{array}$ & $\begin{array}{c}\text { Percentile } \\
\text { score }\end{array}$ \\
\hline & & & & & & & \\
100 & 45.58 & 19.90 & 46.50 & 101.32 & 14.11 & 18.02 & 100 \\
90 & 41.32 & 21.10 & 45.30 & 89.819 & 13.39 & 16.52 & 90 \\
80 & 37.05 & 22.30 & 44.10 & 78.322 & 12.67 & 15.02 & 80 \\
70 & 32.79 & 32.50 & 42.9 & 66.842 & 11.95 & 13.52 & 70 \\
60 & 28.56 & 24.70 & 41.70 & 55.326 & 10.23 & 12.02 & 60 \\
50 & 24.27 & 25.90 & 40.50 & 43.830 & 10.51 & 10.52 & 50 \\
40 & 20.00 & 27.10 & 39.30 & 32.333 & 9.790 & 9.020 & 40 \\
30 & 15.75 & 28.30 & 38.10 & 20.836 & 8.350 & 7.520 & 30 \\
20 & 11.79 & 29.50 & 36.90 & 9.3380 & 7.630 & 6.020 & 20 \\
10 & 7.230 & 30.70 & 35.70 & -2.1590 & 6.910 & 4.520 & 10 \\
Zero & 2.960 & 29.50 & 34.50 & -13.656 & 6.190 & 3.020 & Zero \\
\hline
\end{tabular}

Table 3. The ultimate step of the stepwise regression analysis of the variables of visual perception, auditory perception, kinetic sense, and associated emotional condition on the degree of skill performance $(n=24)$.

\begin{tabular}{lccccc}
\hline \multicolumn{1}{c}{ Variables } & $\begin{array}{c}\text { Partial regression } \\
\text { coefficient }\end{array}$ & $\begin{array}{c}\text { The standard } \\
\text { error }\end{array}$ & $\begin{array}{c}\text { Degrees of } \\
\text { freedom }\end{array}$ & $\begin{array}{c}\text { calculated (t) } \\
\text { value }\end{array}$ & $\begin{array}{c}\text { Contribution } \\
\text { Percentage }\end{array}$ \\
\hline & & & & & \\
& & & & -4.579 & 00 \\
constant coefficient & 306.447 & 1.716 & -3.282 & 0.531 \\
Kinetic Sense & 7.853 & 0.159 & 4 & 2.800 & 0.307 \\
Associated Emotional Condition & 0.165 & 17.33 & & 4.752 & 0.137 \\
Auditory Perception & 82.353 & 0.086 & & 2.800 & 0.005 \\
Visual Perception & -0.282 & & Total & 0.980 \\
& & & & & \\
\end{tabular}

Table 4. The ultimate step of the stepwise regression analysis of specific physical abilities on the standard score of skill performance in soccer $(\mathrm{n}=24)$.

\begin{tabular}{|c|c|c|c|c|c|}
\hline Variables & $\begin{array}{c}\text { Partial regression } \\
\text { coefficient }\end{array}$ & $\begin{array}{l}\text { The standard } \\
\text { error }\end{array}$ & $\begin{array}{c}\text { Degrees of } \\
\text { freedom }\end{array}$ & $\begin{array}{l}\text { calculated }(\mathrm{t}) \\
\text { value }\end{array}$ & $\begin{array}{l}\text { Contribution } \\
\text { Percentage \% } \\
\end{array}$ \\
\hline constant coefficient & -19.608 & 42.231 & \multirow{11}{*}{9} & -0.464 & 0000 \\
\hline Running $800 \mathrm{~m}$ & 9.347 & 4.545 & & 2.057 & 29.80 \\
\hline Successive stations & 15.272 & 6.326 & & -2.414 & 20.40 \\
\hline Wall passing & 0.826 & 0.391 & & 0.211 & 13.20 \\
\hline Stand metatarsal on wooden cube & 0.840 & 0.709 & & 1.189 & \multirow{2}{*}{6.700} \\
\hline Bend the trunk forward to the bottom & 5.074 & 3.333 & & 1.522 & \\
\hline Standing vertical jump & 1.460 & 0.623 & & 2.343 & \multirow{2}{*}{5.400} \\
\hline Running $30 \mathrm{~m} . \times 5$ once & -0.936 & 0.648 & & -1.443 & \\
\hline Running $30 \mathrm{~m}$ & 9.574 & 4.899 & & 1.954 & 4.000 \\
\hline \multirow[t]{2}{*}{ Barrow Zigzag Run } & 0.242 & 1.709 & & 0.142 & 2.000 \\
\hline & & & & Total & 81.50 \\
\hline
\end{tabular}

\section{DISCUSSION}

Table 3 indicates that kinetic sense is the primary contributor in standard score of skill performance in soccer. The researcher attributes this fact to that compatibility neuromuscular has a significant role in getting high accuracy in guiding the kinetic response. This is what increased the value of the contribution rate as the compatibility between the nervous and muscular system has a great importance to the success of any response or skill, whether simple or complex. This is consistent with what concluded by Abu Abdo (2), who emphasized that the kinetic foundations play an important role in the process of compatibility in the activity of the skills that require a distinction between the ir various parts. The associated emotional condition was the 2nd contributor to the standard score of skill performance in soccer. The researcher explains that in the light of that the lower stimulation central nervous system has the more kinetic control and accuracy. Therefore, sample individuals have become able to control over their 
emotions and to isolate them. The idea confirms the mood, and the mood generates the act. Abu Abdo (3) emphasized that the player characterized with psychological balance has the ability to control his/her behavior during the situations featured by a strong emotion. It appears in the cases of failure, defeat, fatigue, and obstacles characterized by a high degree of difficulty. The auditory perception has been the 3rd contributor in the standard score of skill performance in soccer under study. The researcher attributes that to the hearing sense when it is compatible with the sight sense. This will lead to a better image of the targeted work to be learned, and hence, to form a comprehensive kinetic programs, containing multiple aspects. This in turn leads to better learning, including all the variables related to the environment. This is what was confirmed by Shimon (11). He suggested that the brain takes a picture of the surrounding, either by sight and collecting visual information or by hearing. The brain converts this indicative and descriptive information to an image intervening in the brain and handled better. The visual perception has been the 4 th contributor in the standard score of skill performance in the soccer. The researcher explains that the use of visual perception will lead to the possibility of discovering the negative cases in the kinetic image drawn in the brain in the form of kinetic program, and therefore processed through repetition and errors correction. This is what the players perform in the daily skill training. This is also what indicated by Shimon (11) that visual perception is linked to different sensations in the human body, especially the sight sense and its ability to transfer the visual stimuli to the brain. In addition, the sight sense is able to identify the main stimulus and real processing for this stimulus and choosing an appropriate response to it. These aspects of intellectual perception have contributed collectively by $96.8 \%$ in standard score of skill performance in soccer. This is emphasized the importance of the intellectual perception as it is a cognitive character of the organism. It is a key factor in developing kinetic skills and performance. Shimon (11) emphasized that kinetic perception plays an important role in developing the abilities and the level of the individual athlete. The perception involves a composite feature and optical and kinetic components. It is essential to associate between visual perception and the thinking aspect resulting from the oral explanation of the kinetic skill. The predictive equation of predicting the standard score of soccer players' performance from the age of 16-18 years in the significance of specific physical abilities and the variables of the intellectual perception to which they contribute becomes as follows:

The standard score of skill performance in soccer of age $16-18$ years $=306.447+7.853$ (kinetic sense by score) + 0.165 (associated emotional condition by score) +82.353 (auditory perception by score) -0.282 (visual perception by score) (1).

Table 5. The ultimate step of the stepwise regression analysis for specific physical abilities, kinetic sense, associated emotional condition, auditory perception, and standard score of skill performance in soccer under study $(n=24)$.

\begin{tabular}{|c|c|c|c|c|c|}
\hline Variables & $\begin{array}{c}\text { Partial regression } \\
\text { coefficient }\end{array}$ & $\begin{array}{l}\text { The standard } \\
\text { error }\end{array}$ & $\begin{array}{c}\text { Degrees of } \\
\text { freedom }\end{array}$ & $\begin{array}{l}\text { calculated }(t) \\
\text { value }\end{array}$ & $\begin{array}{l}\text { Contribution } \\
\text { Percentage \% }\end{array}$ \\
\hline constant coefficient & -173.97 & 123.998 & \multirow{14}{*}{12} & -1.403 & 00 \\
\hline Kinetic Sense & -0.142 & 1.108 & & -0.128 & 46.60 \\
\hline Successive stations & -14.372 & 6.539 & & -2.198 & 13.00 \\
\hline Barrow Zigzag Run & 0.181 & 1.64 & & 0.546 & 6.30 \\
\hline Bend the trunk to bottom & 0.389 & 0.714 & & 0.546 & 6.20 \\
\hline The metatarsal on wooden cube & 6.326 & 3.200 & & 1.977 & \multirow{2}{*}{5.10} \\
\hline Running $30 \mathrm{~m} . \times 5$ once & 10.129 & 4.329 & & -0.536 & \\
\hline Running 30 Meter & -0.752 & 1.036 & & 2.188 & 5.00 \\
\hline Associated Emotional Condition & 0.996 & 1.036 & & 0.961 & 4.20 \\
\hline Auditory Perception & 0.997 & 0.606 & & 0.961 & 3.80 \\
\hline Standing vertical jump & 1.382 & 0.606 & & 2.281 & \multirow{2}{*}{3.50} \\
\hline Wall passing & 0.092 & 0.423 & & -0.220 & \\
\hline \multirow[t]{2}{*}{ Running and walking $800 \mathrm{~m}$} & 8.727 & 4.412 & & 1.978 & 3.10 \\
\hline & & & & Total & 96.80 \\
\hline
\end{tabular}


Table 4 demonstrated that (running for $800 \mathrm{~m}$ ) test is the primary contributor in standard score of skill performance in soccer under study. This indicates that this specific physical ability is so significant to influence the standard score of skill performance in the soccer players of age 16 - 18 years. This result is consistent with those concluded by Ismail et al. (7). The results of their reference survey of 15 soccer references concluded that endurance gets the primary place in the components order of the specific physical preparation in soccer by $93.3 \%$ of the total experts' opinions. Helmi (8), through his survey study of the experts views about identifying the components of specific physical abilities of soccer players, concluded that endurance get $100 \%$ of the total experts views in the scientific literature. It is noteworthy that these results are consistent with those concluded by Rifai (9) in terms of that the player who possessed a high degree of endurance was able to perform his duties. However, if he lost this trait or his possession became less, his performance would be less and give full opportunity to competitor to get fully control. The successive stations test has been the second contributor in the standard score of skill performance in the soccer under study. The researcher attributes this to what is required by the skill performance conditions of speed endurance during the playing time, at least 45 minutes under the pressure of moving in the playground. The Wall passing test has been the third contributor in the standard score of skill performance in the soccer under study. The researcher explains this result in the light of the conditions required for the skill performance of performance endurance during the game. Both stand metatarsal on wooden cube and bending the trunk forward to the bottom tests have been the fourth contributor in the standard score of skill performance in the soccer under study. The researcher attributes this result to the conditions required for the skill performance of the player's possession of the spine flexibility and stretching the muscle behind the thighs. Both standing vertical jump and running $30 \mathrm{~m} . \times 5$ times tests have been the fifth contributor in standard score of skill performance in the soccer under study. The researcher explains this result in the light of the conditions required for the skill performance of the explosive power. The running $30 \mathrm{~m}$. test has been the sixth contributor in standard score of skill performance in the soccer under study. The researcher attributes this result to the conditions required for the skill performance of the accuracy of shooting on goal or passing the ball to a colleague. Barrow zigzag run test has been the seventh contributor in the standard score of skill performance in the soccer under study. The researcher explains this result in the light of the conditions required for the skill performance of agility and lightness during the game. It is noteworthy that the results of this study consistent with the experts view in identifying the components of physical fitness. However, the results differed in the order of importance of these components according to their contributions ratio to the standard score of skill performance of soccer players from 1618 years under study. They also added the compatibility and accuracy as specific physical components, which have an impact on the skill performance of the soccer players. The standard score of skill performance in the significance of specific physical variables contributed to the soccer players canbe predicted by using the following equation:

The standard score of skill performance in soccer from the age of 16-18 years $=-19.608+9.347$ (Running for $800 \mathrm{~m}$ per second) +15.272 (Successive Stations +0.826 (Wall passing by number) 0.848 (The metatarsal on wooden cube) +5.074 (Bending the trunk forward to the bottom by $\mathrm{cm}) .+1.460$ (Standing vertical jump) +9.574 (Running for $30 \mathrm{~m} \times 5$ times per second) - 0.936 (Running $30 \mathrm{~m}$. per second) stations per second) +0.242 (Barrow Zigzag Run per second).......(2).

The researcher explains these correlatively proportional and reverse relationships in the light of that the most important requirements for the soccer player success is the acquisition of the public and specific physical fitness so that he can perfectly achieve his duties in the game. Abu Abdo (2) indicated that the physical fitness works on developing and improving the physical and kinetic status to confront the burdens of the requirements of training process and competition during games with minimal effort and with the ability to quickly restore the formation of energy sources.

Bisatti (5) suggested that some critical physical and intellectual abilities. The physical requirements are varied in terms of quality, quantity and timing of their execution according to the type and privacy of each skill. The deficiency of the player's acquisition, whether young player or senior player, of those physical factors or lack of them, obviously reflects the weakness of skill level of them. Balanced development of all the specific physical attributes is, 
thereby, considered as one of the basic directions of the training process, which must be observed by the coach. It is also considered as a basis upon which the player's ability is based to increase the perfectly skill performance. It is noteworthy that the results of this study are consistent with what concluded by Rifai (9) in terms of modern soccer requires attention to the development and the evolution of the following factors: 1) Endurance, 2) Muscle strength, 3) Velocity, 4) Agility, and 5) Flexibility.

The results of the Stepwise regression analysis of specific physical abilities, visual perception, the auditory perception, kinesthetic perception, and associated emotional condition on the standard score of the skill performance of soccer players from 16 - 18 years under study, table 5, indicated that kinetic sense is the primary contributor to the standard score of skill performance in soccer under study. It is followed by the selection of successive stations, Barrow Zigzag Run test followed by bend trunk to bottom test, both the metatarsal on wooden cube and Running for $30 \mathrm{~m} \times 5$ times tests, , then the associated emotional state, next auditory perception, after that standing vertical jump test and wall passing, finally running and walking for $800 \mathrm{~m}$, respectively. It is noteworthy that the variables of specific physical abilities, kinetic sense, associated emotional condition, and auditory perception have collectively contributed with $96.80 \%$ in the standard score of skill performance in soccer under study. It is a relatively high ratio, indicating that the specific physical abilities are so significant in influencing the skill performance of soccer players. The results of this study are consistent with those related to the field of research, indicating that the specific physical fitness is so important and it has an effect on the skill preparation such as Scriber (10), Towson(12). The predictive equation for predicting the standard score of soccer players performance from the age of 16 - 18 years in the significance of specific physical abilities and the intellectual perception variables, contributing to it has become as follows:Standard score of the soccer players' performance from the age of $16-18$ years $=-173.97-0.142$ (Kinetic Sense) - 14.372 (Successive Stations) + 0.181 (Barrow Zigzag Run) +0.389 (Bending the trunk to bottom) +6.326 (Standing metatarsal on wooden cube) +10.129 (Running for $30 \mathrm{~m} \times 5$ times) - 0.752 (Running for 30m) +0.996 (Associated Emotional Condition) + 0.997 (Auditory perception) + 1.382 (Standing Vertical Jump) +0.092 (Wall Passing) +8.727 (Running, walking for $800 \mathrm{~m}$ )...(3)
It is obvious from the foregoing that the research questions have been answered.

In conclusion; the specific physical abilities and the determinants of intellectual perception have been arranged in descending order according to their contribution ration to the standard score of skill performance in the soccer of age $16-18$ years as follows:

- Kinetic sense with contribution rate $46.6 \%$.

- Successive stations (performance endurance) with contribution rate $13.00 \%$

- Barrow zigzag run (Agility) with contribution rate $6.30 \%$.

Bending the trunk forward to the bottom (Flexibility) with contribution rate $6.20 \%$.

- Standing metatarsal on wooden cube (Balance) + Running for $30 \mathrm{~m} \times 5$ times (Speed Endurance) with contribution rate $5.10 \%$.

Running for 3m (Transitive speed) + running for $3 \mathrm{~m} \times 5$ Times (velocity endurance) with contribution rate $5.0 \%$.

- Associated emotional condition with contribution rate $3.20 \%$.

- Auditory perception with contribution rate $4.80 \%$.

- Standing vertical jump (explosive power of both legs) + wall passing with contribution rate $3.50 \%$.

- Running and walking for $800 \mathrm{~m}$ (periodic respiratory endurance) with contribution rate $3.10 \%$.

The predictive equation of predicting the standard score of soccer players' performance from the age of 16-18 years in the significance of specific physical abilities and the variables of the intellectual perception to which they contribute becomes as obvious equation (3).

\section{REFERENCES}

1. Abdel Khaliq E. Sports training, Theories, Applications, 11 $1^{\text {th }}$ edition, Alexandria: Munshaat al-Marif, 2003, 186.

2. Abu Abdo HA. The Recent Trends in Football Planning and Training, 1st edition, Alexandria: Alishaa Library, 2001, 37, $133,107$.

3. Abu Abdo HA. The Skill Preparation in Football, 2nd edition, Alexandria, 1999, 40. 
4. Abul-Magd A, Alnmacai JI. Planning of Education and Training Programs of Youngsters and Youth in Football Cairo: El-Ketab for Publication, 1997.

5. Bisatti AA. Physical training and Fitness in Soccer, Alexandria: Munshaat al-Marif, 1994, 83, 111, 141, 169, 191.

6. Ismail T, Abul-Magd A, Shaalan I. Football between Theory and Practice, Physical Fitness, Cairo: Dar El-Fiker Al-Arabi, 1989.

7. Moghnosi P, Marci MV, Sttori MD, Lorenzelli F. The relation and kicking ball speed with beginners. Italy, 1994.

8. Ramadan RH. A scientific production titled, The Impact of a Training Program for Physical Fitness at the Level of Skill Performance and the Results of the Matches of the Football Players under 18 Years, 1999.
9. Rifai MH. A scientific production entitled, The Effect of Some Specific Exercises on the Shooting Accuracy and the Accurate Performance of Penalty in Football, 2005.

10. Scriber K. Estimated maximum oxygen uptake in college football players during of training and detraining. Applied Research in Coaching and Athletics. Boston, 1990.

11. Shimon MA. The Intellectual Training in the Sports Field, 1st edition, Cairo: Dar El-Fiker Al-Arabi, 1996, 292, 496, 497.

12. Towson, IM. The Contribution of Some biomechanical and Physical Variables, Influencing on the Level of Skill Performance to Drop to the Ground to Catch the Ball for Goalkeepers, Master Thesis, Faculty of Physical Education for Boys in Zigzag, Zigzag University.

\section{Appendix}

Appendix 1 . The validity coefficients of both specific physical abilities and intellectual training tests under study by using the discriminate method $(\mathrm{n} 1=\mathrm{n} 2=7)$.

\begin{tabular}{|c|c|c|c|c|c|c|c|c|}
\hline \multirow[t]{2}{*}{ Variables } & \multirow{2}{*}{$\begin{array}{l}\text { Measurement } \\
\text { Unit }\end{array}$} & \multicolumn{2}{|c|}{ Practitioners } & \multicolumn{2}{|c|}{$\begin{array}{c}\text { Non- } \\
\text { practitioners }\end{array}$} & \multirow{2}{*}{$\begin{array}{c}\text { calculated } \\
\text { (t) value }\end{array}$} & \multirow{2}{*}{$\begin{array}{c}\text { Degrees } \\
\text { of } \\
\text { freedom }\end{array}$} & \multirow{2}{*}{$\begin{array}{c}\text { Validity } \\
\text { coefficien } \\
\sqrt{\text { eta }^{2}}\end{array}$} \\
\hline & & Mean & $\mathrm{SD}$ & Mean & SD & & & \\
\hline Running 800m & Sce. & 61.08 & 21.29 & 28.30 & 9.59 & $3.533^{*}$ & & 0.8290 \\
\hline Wall passing & Sce. & 77.07 & 10.41 & 39.10 & 10.26 & $6.940^{*}$ & & 0.9690 \\
\hline stop ball from different heights & $\mathrm{m}$. & 7.44 & 2.60 & 2.76 & 0.69 & $5.613^{*}$ & & 0.9120 \\
\hline $\begin{array}{l}\text { Bend the trunk forward to the } \\
\text { bottom }\end{array}$ & $\mathrm{m}$. & 64.97 & 16.93 & 37.32 & 11.55 & $5.568^{*}$ & & 0.9140 \\
\hline Standing vertical jump & $\mathrm{m}$. & 45.85 & 4.320 & 35.40 & 5.990 & $13.87-^{*}$ & & 0.9130 \\
\hline Running $30 \mathrm{~m} . \times 5$ once & Sce. & 26.50 & 4.52 & 40.50 & 3.25 & $10.520^{*}$ & 5 & 0.9650 \\
\hline Running 30m & Sce. & 4.2050 & 0.451 & 6.304 & 0.84 & $12.54-^{*}$ & & 0.9250 \\
\hline Successive stations & Sce. & 4.2050 & 1.840 & 15.20 & 3.450 & $6.780^{*}$ & & 0.9270 \\
\hline Barrow Zigzag Run & Sce. & 1.5200 & 1.52 & 6.304 & 0.70 & $6.540^{*}$ & & 0.9850 \\
\hline $\begin{array}{l}\text { Hit the ball with the sole of the foot } \\
\text { side of the small goal }\end{array}$ & point & 28.60 & 2.45 & 8.60 & 1.65 & $8.950^{*}$ & & 0.9150 \\
\hline Stand metatarsal on wooden cube & Sce. & 1.5200 & 30.50 & 4.20 & 2.870 & $7.540^{*}$ & & 0.9450 \\
\hline Kinetic Sense & point & 18.50 & 2.820 & 4.620 & 10.60 & $5.680^{*}$ & & 0.9680 \\
\hline Associated Emotional Condition & point & 17.60 & 2.750 & 3.550 & 11.40 & $5.560^{*}$ & & 0.9700 \\
\hline Auditory Perception & point & 15.80 & 1.980 & 3.550 & 8.950 & $15.54^{*}$ & & 0.9610 \\
\hline Visual Perception & point & 16.80 & 2.620 & 3.850 & 9.450 & $7.540^{*}$ & & 0.9780 \\
\hline
\end{tabular}

${ }^{*}$ Tabulated $(\mathrm{t})$ value at a statistical significance level of 0.01 to the significance of the two parties $=2.980$

Appendix 2.The validity coefficients of the skill tests, by using the discriminate method ( $\mathrm{n} 1=\mathrm{n} 2=7$ )

\begin{tabular}{|c|c|c|c|c|c|c|c|c|}
\hline \multirow{2}{*}{ Variables } & \multirow{2}{*}{$\begin{array}{l}\text { Measurement } \\
\text { Unit }\end{array}$} & \multicolumn{2}{|c|}{ Practitioners } & \multicolumn{2}{|c|}{ Non-practitioners } & \multirow{2}{*}{$\begin{array}{l}\text { Calculated } \\
\text { (t) value }\end{array}$} & \multirow{2}{*}{$\begin{array}{l}\text { Degrees } \\
\text { of } \\
\text { freedom }\end{array}$} & \multirow{2}{*}{$\begin{array}{c}\text { Validity } \\
\text { coefficient } \\
\sqrt{\text { eta }^{2}}\end{array}$} \\
\hline & & Mean & SD & Mean & SD & & & \\
\hline $\begin{array}{l}\text { Kicking the ball for the longest } \\
\text { distance }\end{array}$ & $\mathrm{m}$. & 63.79 & 16.930 & 15.400 & 5.5512 & $5.5689^{*}$ & & 0.9140 \\
\hline Zigzag running with soccer ball & Sce. & 39.61 & 11.291 & 48.100 & 9.5940 & $3.533^{*}$ & 5 & 0.8290 \\
\hline $\begin{array}{l}\text { Hit the ball with the sole of the } \\
\text { foot side of the small goal }\end{array}$ & point & 9.80 & 2.4500 & 4.4200 & 1.6000 & $0.590^{*}$ & & 0.9660 \\
\hline Dribbling the ball on both feet & Sce. & 25.62 & 10.318 & 15.500 & 7.3110 & $5.579^{*}$ & & 0.9180 \\
\hline $\begin{array}{l}\text { Hit the ball with the head } \\
\text { farthest distance }\end{array}$ & $\mathrm{m}$. & 10.50 & 2.7000 & 3.4000 & 10.264 & $6.940^{*}$ & & 0.9690 \\
\hline $\begin{array}{l}\text { Throw-in to the farthest } \\
\text { distance }\end{array}$ & $\mathrm{m}$. & 11.25 & 2.6000 & 2.7580 & 0.6930 & $5.613^{*}$ & & 0.9120 \\
\hline
\end{tabular}

* Tabulated $(\mathrm{t})$ value at the level of statistical significance 0.01 to the significance of two parties $=2.98$. 
Appendix 3. Analysis of reliability, balance, split of reliability coefficients of specific physical abilities and intellectual perception $(n=8)$.

\begin{tabular}{cccccccc}
\hline $\begin{array}{c}\text { The } \\
\text { correlation } \\
\text { among } \\
\text { components }\end{array}$ & $\begin{array}{c}\text { Equivalent } \\
\text { length of } \\
\text { Spearman }\end{array}$ & $\begin{array}{c}\text { Guttmann } \\
\text { Split-Half }\end{array}$ & $\begin{array}{c}\text { In equivalent } \\
\text { length of } \\
\text { Spearman }\end{array}$ & Part I Error & Part II Error & $\begin{array}{c}\text { The factors } \\
\text { number of the } \\
1^{\text {st }} \text { part }\end{array}$ & $\begin{array}{c}\text { The factors } \\
\text { number of the } \\
\text { second part }\end{array}$ \\
\hline 0.6633 & 0.7976 & 0.7794 & 0.7976 & -0.0096 & 0.8585 & 7 & 8 \\
\hline
\end{tabular}

Appendix 4. Analysis of reliability, balance, split of reliability coefficients of the skill tests $(n=8)$.

\begin{tabular}{cccccccc}
\hline $\begin{array}{c}\text { The correlation } \\
\text { among } \\
\text { components }\end{array}$ & $\begin{array}{c}\text { Equivalent } \\
\text { length of } \\
\text { Spearman }\end{array}$ & $\begin{array}{c}\text { Guttmann } \\
\text { Split-Half }\end{array}$ & $\begin{array}{c}\text { In equivalent } \\
\text { length of } \\
\text { Spearman }\end{array}$ & $\begin{array}{c}\text { Part I } \\
\text { Error }\end{array}$ & $\begin{array}{c}\text { Part II } \\
\text { Error }\end{array}$ & $\begin{array}{c}\text { The factors } \\
\text { number of } \\
\text { the } 1^{\text {st }} \text { part }\end{array}$ & $\begin{array}{c}\text { The factors } \\
\text { number of the } \\
\text { second part }\end{array}$ \\
\hline 0.9141 & 0.9551 & 0.7204 & 0.9551 & 0.6708 & 0.5194 & 3 & 3 \\
\hline
\end{tabular}

